\title{
A Study of Mycetism: Study of Outbreak of Mushroom Poisoning in a Village in Western Ghats of Maharashtra
}

\author{
Patil V S, Patil G V, Gholpe D B
}

\begin{abstract}
This is the study of outbreak of Mushroom-poisoning in Sept. 2015 in a village, Padalwadi, near Gaganbawada taluka of Kolhapur district. Mushroom poisoning or mycetism is not a very widely discussed topic. Few historical cases are noted. Material \& method - cases admitted to emergency ward of teaching hospital. Pattern of clinical presentation \& outcome was noted. 11 patients of mycetism were admitted in our hospital in the month of September 2015. All had symptoms like cholinergic syndrome. All were treated symptomatically. One week later all are doing well. This study is to know more about presentation of mushroom poisoning.
\end{abstract}

Keywords: Mycetism, Cholinergic Syndrome, Mushroom poisioning

\section{Introduction}

11 patients were admitted following consumption of mushrooms plucked by a person who visited the woods near the fields. They were distributed in neighbors; who cooked
$\&$ consumed it for morning meals around $11 \mathrm{am}$. Then the symptoms like nausea, increased salivation, sweating, vomiting and diarrhea started around 12-12:30pm. All the patients were rushed to the district hospital by $3 \mathrm{pm}$.

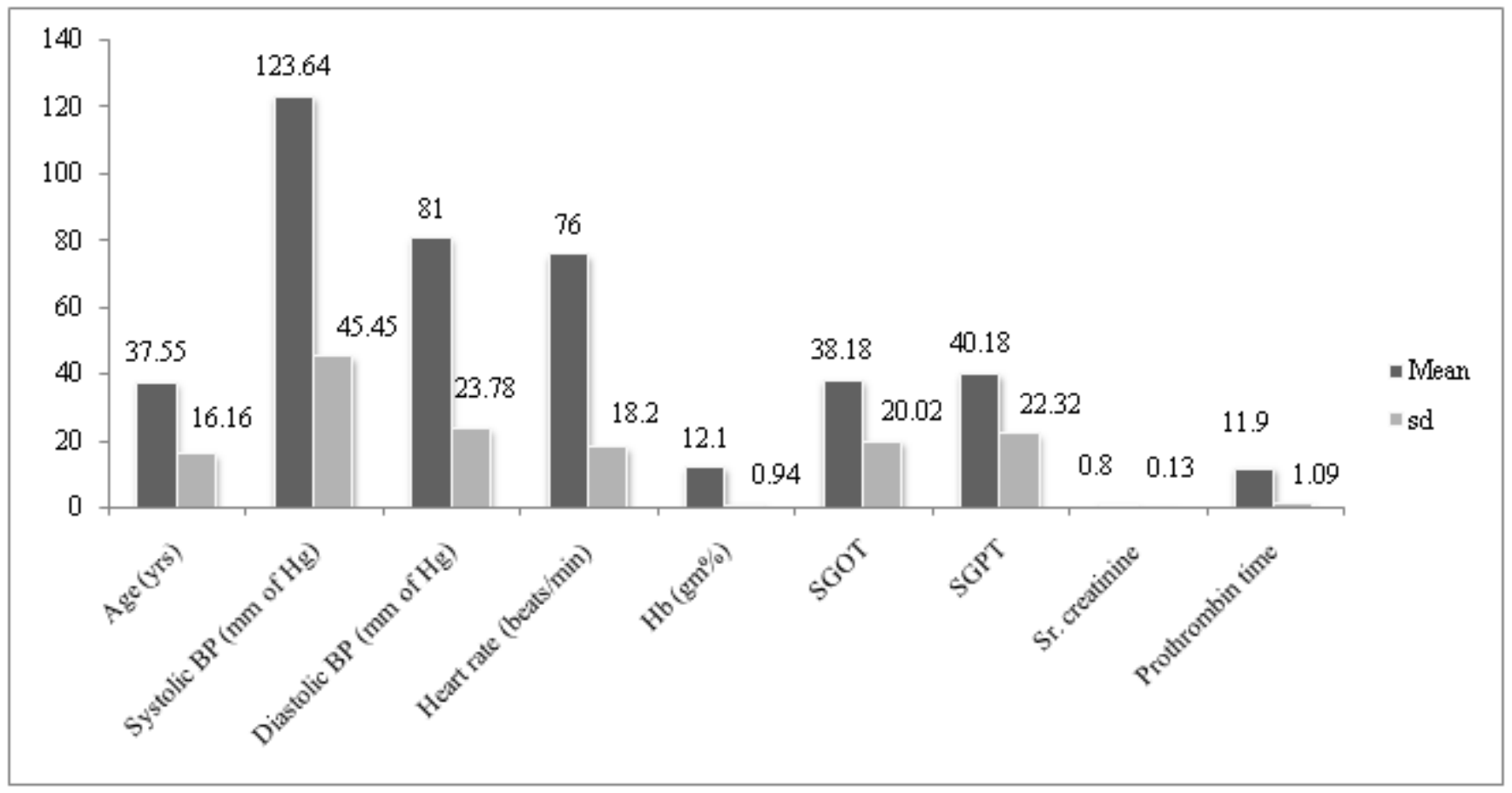

Age and gender distribution - table 1, the age ranged from 16yrs to 66yrs. The mean age being $37.55 \pm 16.1$ yrs. 


\section{International Journal of Science and Research (IJSR)

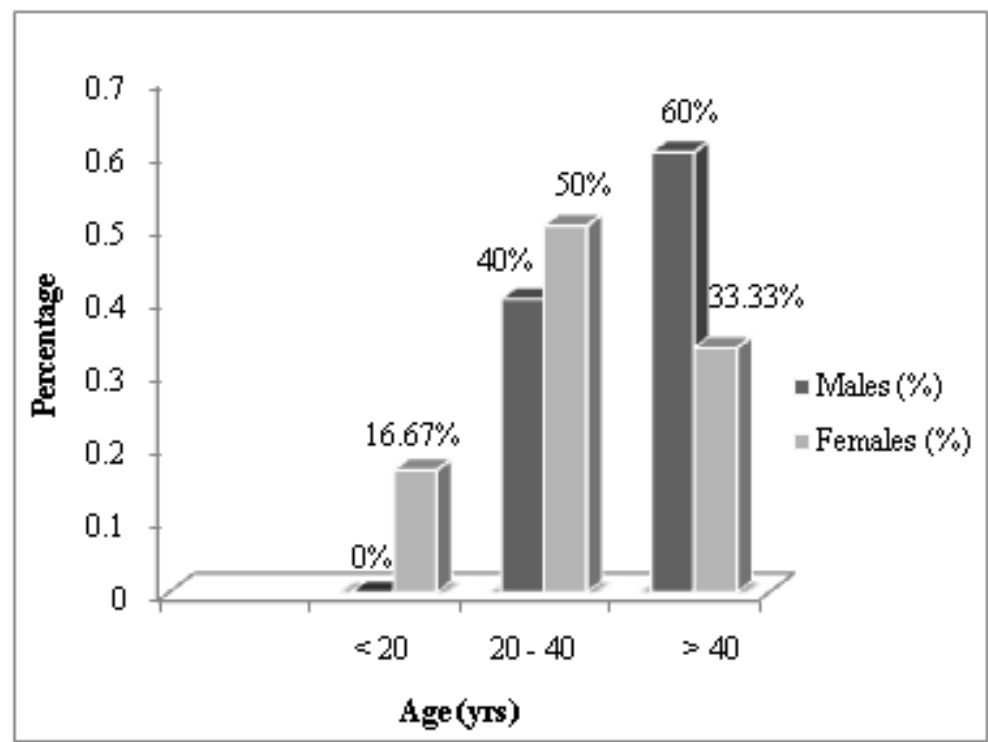

There were 5 male patients and 6 female patients.

The distribution of cases according to symptoms:

All patients had nausea, sweating, increased salivation, vomiting and few had diarrhoea.

On examination, 3 patients had hypotension, 6 had Meiosis, 2 had Bradycardia, 1 had hypertension.

2 of them required vaso-pressure support and responded well within 12 hrs.

All patients with Meiosis, hypotension, Bradycardia were treated with IV atropin(upto3-5amp). All of them responded well to the treatment and were observed upto 3 days in the hospital. LFTs repeated on day 3 were normal. All of them were discharged on day3. Followed up on day7 at PHC Karanjfen. All of them were clinically normal

\section{Discussion}

Mushrooms are fruiting bodies of fungi. Mushroom poisoning mostly result due to growing trend of foraging edible fungi. They are used for food, religious ceremonies and even as medication by herbal healers. Mushrooms are classified according to the effect of toxin they contain-

\begin{tabular}{|l|c|c|}
\hline \multicolumn{1}{|c|}{ Name } & Toxin & Effect \\
\hline 1. Amanita/Galerina & Cyclopeptide & $\begin{array}{c}\text { Fatal Hepatorenal } \\
\text { shutdown. }\end{array}$ \\
\hline $\begin{array}{l}\text { 2. Amanita muscaria } \\
\text { Amanita paterina }\end{array}$ & $\begin{array}{c}\text { Muscimol, } \\
\text { ibotenic acid }\end{array}$ & $\begin{array}{c}\text { Delirium, } \\
\text { Hallucinations. }\end{array}$ \\
\hline 3. Boletus/Inocybe & Muscarin & Cholinergic syndrome. \\
\hline $\begin{array}{l}\text { 4. Coprinus } \\
\text { astramentarius }\end{array}$ & Coprin & $\begin{array}{c}\text { Disulfiram-like reaction } \\
\text { with ethanol. }\end{array}$ \\
\hline
\end{tabular}

\section{Conclusion}

The mushrooms involved in this outbreak probably contain toxin-Muscarin; since many patients had a cholinergic syndrome. Foraging for edible mushrooms needs to be more cautious.

\section{References}

[1] Jeffrey Brent, Robert B. Palmer, Mushrooms

[2] Haddad and Winchester's Clinical management of Poisoning and drug Overdose. 